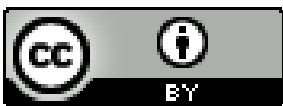

\title{
ESCREVER PARA NÃO SILENCIAR: AFRICANOS, ENFERMIDADES E ACESSO ÀS PRIMEIRAS LETRAS NO SUDESTE ESCRAVISTA, NOTAS DE PESQUISA
}

Iamara da Silva Viana ${ }^{1}$

Resumo: O acesso à escolarização formal na sociedade brasileira teve início com restrições a alguns grupos. Africanos, mesmo livres ou libertos, não poderiam adentrar nos espaços escolares. Eram proibidos por lei, assim como os que padeciam de moléstias contagiosas. Contudo, apreenderam os códigos de escrita e leitura. Foram além, utilizando essa ferramenta em suas visões de mundo, bem como em negociações, apropriações, ações e exigências. Nesse sentido, consideramos, como leitura possível, que as múltiplas experiências das escravidões no Brasil permitiram aos africanos e seus descentes construírem, a partir do domínio dos códigos de escrita e leitura, o letramento, utilizando esse saber na articulação entre política, memória e história. Utilizamos, nesta reflexão, dois documentos: carta escrita por libertos de Paty do Alferes (1889) e o documento de apreensão de um quilombola no Espirito Santo, com a posse de gramática (1861).

Palavras-Chave: Africanos; Educação; Letramento; Escravidão

\section{TO WRITE IN ORDER NOT TO SILENCE: AFRICANS, SICKNESSES AND ACCESS TO THE FIRST LETTERS IN THE SUREST OF SLAVES, RESEARCH NOTES}

\begin{abstract}
The access to formal schooling in Brazilian society, in its beginning, was restricted to some groups. Africans, even those who were free, or the ones who had been freed, couldn't enter schools. They were forbidden by the law, as well as those who were committed with infectious diseases. Despite, they have apprehended the codes of reading and writing. They've gone beyond, using these resources in constructing their point of views, as well as in negotiations, appropriations, actions and demands. In this sense, we consider as a possible interpretation that the multiple experiences of slaveries in Brazil allowed Africans and their descendants to build literacies, out of reading and writing

\footnotetext{
${ }^{1}$ Doutora em História Política pela Universidade do Estado do Rio de Janeiro/UERJ com estágio na École des Hautes Études en Sciences Sociales/EHESS, Paris; Professora do Departamento de História da Pontifícia Universidade Católica do Rio de Janeiro/PUC-Rio; Email: ia.svivana@gmail.com
}

Revista da ABPN • v. 12, n. Ed. Especial - Caderno Temático: "Africanos, escravizados, libertos biografias, imagens e experiências atlânticas” • agosto de 2020, p. $392-409$ 
domain, using these skills to articulate politics, memory and history. We have two documents as sources to propose our reflection: the letter written by freed slaves form Paty de Alferes (1889) and the document apprehended of a quilombola in Espírito Santo, with grammar (1861).

Keywords: Africans; Education; Literacy; Slavery

\section{ESCRIBIR PARA NO SILENCIAR: AFRICANOS, ENFERMEDADES Y ACCEDO A LAS PRIMERAS LETRAS EN EL SUDESTE ESCLAVISTA, NOTAS DE INVESTIGACIÓN}

Resumen: El acceso a la educación formal en la sociedad brasileña comenzó con restricciones a algunos grupos. Los africanos, incluso libres o liberados, no podían entrar en los espacios escolares. Estaban prohibidos por la ley, al igual que los que sufrían de enfermedades contagiosas. Sin embargo, se apoderaron de los códigos de escritura y lectura. Fueron más allá, utilizando esta herramienta en su cosmovisión, así como en negociaciones, apropiaciones, acciones y demandas. En este sentido, consideramos, como posible lectura, que las múltiples experiencias de esclavitud en Brasil permitieron a los africanos y sus descendientes construir, desde el dominio de la escritura y la lectura de códigos, la alfabetización, utilizando este conocimiento en la articulación entre la política, la memoria y la historia. En esta reflexión, utilizamos dos documentos: una carta escrita por los hombres libres de Paty do Alferes (1889) y el documento de incautación de una quilombola localizada en Espíritu Santo, con la posesión de la gramática (1861).

Palabras-clave: Africanos; Educación; Alfabetización; Esclavitud

\section{ÉCRIRE POUR NE OUBLIER PAS: AFRICAINS, MALADIES ET ACCÈS AUX PREMIÈRES LETTRES DANS LE SUD-EST DES ESCLAVES, NOTES DE RECHERCHE}

Résumé: L'accès à l'école formelle dans la société brésilienne a commencé avec des restrictions pour certains groupes. Les Africains, même libres ou libérés, ne pouvaient pas entrer dans les écoles. Ils sont interdits par la loi, tout comme ceux qui souffrent de maladies contagieuses. Cependant, ils ont appris les codes de l'écriture et de la lecture. Ils sont allés plus loin, en utilisant cet outil dans leurs visions du monde, ainsi que dans les négociations, les crédits, les actions et les exigences. En ce sens, nous considérons, comme lecture possible, que les multiples expériences de l'esclavage au Brésil ont permis aux Africains et à leurs descendants de construire l'alphabétisation, en utilisant le domaine de l'écriture et de la lecture des codes, en utilisant ces connaissances dans l'articulation entre politique, mémoire et histoire. Dans cette réflexion, nous avons utilisé deux documents: une lettre écrite par des affranchis de Paty do Alferes (1889) et le document d'appréhension d'une quilombola à Espirito Santo, avec possession de grammaire (1861).

Revista da ABPN • v. 12, n. Ed. Especial - Caderno Temático: "Africanos, escravizados, libertos biografias, imagens e experiências atlânticas" • agosto de 2020, p. $392-409$ 


\section{INTRODUÇÃO}

Em 19 de abril de 1889, um grupo de libertos, por meio de uma carta, exigiam educação para seus filhos. Formavam a "Comissão de Libertos de Paty de Alferes". Documento riquíssimo e raro para historiadores da escravidão, a carta fora enviada para Ruy Barbosa, apresentando diferentes possibilidades de análise, a partir da suposta escrita dos ex-escravizados. Ao se dirigirem ao "grande cidadão", requeriam auxílio para a "educação e instrução" de seus filhos. O destinatário não fora escolhido aleatoriamente, posto mencionarem a relevância do "auxílio da invejável ilustração e do grande talento" daquele jornalista, intelectual, abolicionista e republicano. Ruy Barbosa era um homem das letras e congregava, o que para aqueles libertos seriam os elementos fundamentais para mobilizar o interesse de tão grande prestígio.

$\mathrm{Na}$ mesma carta afirmavam que a liberdade havia sido "conquistada pelo povo e não dada pela rainha". A liberdade referenciada aludia a lei de 13 de maio de 1888, um dentre muitos outros sentidos de liberdade. A afirmação dos libertos, contudo, demonstra visão peculiar acerca do evento da assinatura da lei Áurea pela princesa Isabel, apresentada em muitos periódicos como a "Redentora". Enquanto os jornais do país destacavam a Abolição como ato relacionado ao Império do Brasil, os ex-escravizados de Paty do Alferes apontavam sua participação enquanto povo para a libertação dos negros africanos ainda escravizados, e de seus descendentes. Leitura difundida em muitos manuais e livros didáticos até o século XX. Afinal, na disputa que ocorrera após o 13 de maio, republicanos e monarquistas tentavam impor seus ideais e pensamentos, destacando-se o papel da guarda negra e sua visão acerca da abolição e da monarquia, demonstrando a complexidade que envolvia diferentes atores políticos (GOMES, 1005). $\mathrm{O}$ documento já fora mencionado em outros trabalhos ${ }^{2}$, mas aqui quero registrar que, para

\footnotetext{
${ }^{2}$ Sobre a Carta dos libertos ver: ALBUQUERQUE, Wlamyra R. de. O jogo da dissimulação: abolição e cidadania negra no Brasil. São Paulo: Companhia das Letras, 2009.; GOMES, Flavio. Negros e política (1888-1937). Rio de Janeiro: ZAHAR, 2005.; VIANA, Iamara; GOMES, Flávio; NETO, Alexandre. Escritos insubordinados entre escravizados e libertos no Brasil. Estudos Avançados 33 (96). pp. 155-177.; NETO, Alexandre Ribeiro. Acalanto: ensinando as primeiras letras aos filhos de libertos em Vassouras (1871-1910). In: CORD, Marcelo Mac; ARAÚJO, Carlos Eduardo Moreira de; GOMES, Flávio dos Santos
}

Revista da ABPN • v. 12, n. Ed. Especial - Caderno Temático: "Africanos, escravizados, libertos biografias, imagens e experiências atlânticas" • agosto de 2020, p. $392-409$ 
além de dominar os códigos de escrita e leitura, aqueles libertos dominavam os códigos culturais e políticos. Conheciam, ainda que não profundamente, parte da legislação e sua utilidade. E mais! Utilizavam seus conhecimentos e saberes para alcançarem seus objetivos, demonstrando leitura peculiar e politizada acerca de questões políticas. Teriam eles se aliado aos “pensadores e intelectuais negros" advindos dos mundos da escravidão? Como teriam esses libertos acessado os códigos de escrita e leitura? De que modo se aproximaram da legislação a ponto de a utilizarem em suas narrativas e argumentação? No caso das moléstias, muitos estariam fora da escola, tendo em vista o alto índice de mortalidade por doenças infecto-contagiosas, então, qual seria o objetivo de pôr na letra da lei a proibição de enfermos nos espaços escolares oficiais? Seria possível indivíduos contagiados por moléstias como tuberculose, febre amarela ou cólera transitarem entre o espaço privado de suas casas, e o público da escola?

\section{ANALISANDO OS CENÁRIOS}

A configuração do cenário descrito nos permite refletir que, diferentemente de apenas deterem a aquisição da escrita, os libertos de Paty do Alferes demonstram ser detentores de "aspectos sócio-históricos da aquisição de um sistema escrito por uma sociedade" (TFOUNI: 1988, p. 16 apud SOARES, 2002). Para Tfouni, enquanto a alfabetização se apresenta como prática individual, o letramento comporta o coletivo. Nele, incluímos ações coletivas políticas, culturais, de resistência e de agência. A alfabetização, nesse sentido, refere-se à aquisição da escrita enquanto aprendizagem de habilidades para leitura, escrita e as chamadas práticas de linguagem. Isso é levado a efeito, em geral, por meio do processo de escolarização e, portanto, da instrução formal nos dias atuais; no entanto, não foi o que ocorreu, provavelmente, com aqueles ex escravizados.

A alfabetização pertenceria, assim, ao âmbito do individual. As práticas de letramentos, por sua vez, "focaliza[m] os aspectos sócio-históricos da aquisição da escrita. Entre outros casos, procura[m] estudar e descrever o que ocorre nas sociedades,

(orgs). Rascunhos Cativos: educação, escolas e ensino no Brasil escravista. 1. ed. Rio de Janeiro: 7 Letras, 2017.

Revista da ABPN • v. 12, n. Ed. Especial - Caderno Temático: "Africanos, escravizados, libertos biografias, imagens e experiências atlânticas” • agosto de 2020, p. 392-409 
quando adotam um sistema de escritura de maneira restrita ou generalizada"; buscando ainda entender "quais práticas psicossociais substituem as práticas "letradas" em sociedades ágrafas" (Idem, 1988, p. 9, e 1995, p. 9-10 apud SOARES: 2002). Importa mencionar que esta análise identifica africanos, livres ou libertos, como agentes que iam além do aprendizado "do ler e do escrever". Exerciam efetivamente práticas sociais de leitura e de escrita, intervindo, apropriando-se de leis, agindo, participando, construindo estratégias, exigindo mudanças sociais. Desse modo, a escrita pode ser pensada como forma de sociabilidade e uso de saberes em prol de um coletivo. Neste caso específico, dos filhos dos libertos e sua escolarização futura.

A Primeira Lei Geral de Educação no Brasil, de 1827, apresentou a gênese do pensamento acerca da defesa de uma estrutura de educação pública. Contudo, aqui nos interessa analisar a Lei n.1 de 1837, e o Decreto no. 15, de $1839^{3}$, sobre Instrução Primária no Rio de Janeiro, aprovada durante a presidência de Paulino José Soares de Sousa. Tendo sido decretada na então capital do Império do Brasil, teve força política e cultural, sendo reproduzida no restante do país até a primeira metade do século XX. Definia em três as classes de ensino das escolas de instrução primária. A primeira abordaria "leitura e escrita, as quatro operações de Aritmética sobre números inteiros, frações ordinárias, e decimais, e proporções: princípios de moral cristã e da religião do Estado; e a gramática da língua nacional". A segunda versaria sobre "noções gerais de geometria teórica e prática" e a terceira dos "elementos de geografia" (BRASIL, 1837).

Os objetivos relativos à instrução primária ficam explícitos em seus artigos, quais fossem instruir indivíduos à prática da leitura, da escrita, das operações matemáticas simples e, como não poderia deixar de ser, da religião que embasava o Império, bem como seus valores e moral. Objetivos pragmáticos, para atender a demandas urgentes de uma sociedade que se pretendia moderna e civilizada. Outra questão relevante está posta no Artigo $3^{\circ}$. Nele, informa-se a quem seria negado o acesso à instrução primária: "pessoas que padecerem de moléstias contagiosas", "os escravos e os pretos Africanos, ainda que sejam livres ou libertos" (BRASIL, 1837). Percebe-se que a liberdade não garantiu a

\footnotetext{
${ }^{3}$ Sobre as principais leis que versaram sobre educação no império do Brasil ver a tese: FERREIRA, Higor Figueira. Com tintas de liberdade: professores, raça e cartografias da Educação na Corte imperial. Defendida no PPGHC do IH/UFRJ, 2019
}

Revista da ABPN • v. 12, n. Ed. Especial - Caderno Temático: "Africanos, escravizados, libertos biografias, imagens e experiências atlânticas" • agosto de 2020, p. $392-409$ 
africanos o direito de frequentar espaços escolares oficiais. O caminho certamente foi a informalidade, afinal, a historiografia tem mostrado, em recentes pesquisas, documentos escritos por escravizados, quilombolas e libertos, como a carta mencionada acima (GOMES; MACHADO, 2017). A segunda metade do oitocentos, seguida pela pósemancipação, apresentou nova configuração, posto existirem professores pretos e exescravizados atuando formal e informalmente. ${ }^{4}$ A proibição garantida pela legislação não coibiu africanos - escravizados, livres ou libertos - de acessarem as primeiras letras, nem mesmo de construírem visões de mundo mediante o contato que estabeleceram com diferentes sujeitos, por meio das sociabilidades construídas a partir da diáspora africana. Mas quem eram os libertos que assinaram a carta?

A pesquisa inicial nos permitiu aproximar-nos da possível identidade do primeiro a assinar a carta, cuja caligrafia muito se parece com a de todo o documento: Quintiliano Avellar (preto). Além dele, a comissão de libertos contou com mais seis membros: Ambrósio Teixeira, João Gomes Batista, Francisco de Salles Avellar, José dos Santos Pereira, Ricardo Leopoldino de Almeida e Sergio Barboza dos Santos. As duas possibilidades que nos permitem essa aproximação da identidade de Quintilliano estão reproduzidas no periódico $O$ Vassourense. Na primeira ocorrência, de 1886, encontramos o primeiro Quintiliano, ex-escravizado de Antonio Gomes Ribeiro de Avellar ${ }^{5}$, residente em Paty de Alferes. Matriculado sob o número 8810, de 13 de agosto de 1872, cor preta, solteiro, trabalhador de lavoura e com 62 anos de idade. O segundo Quintiliano seria exescravizado de Joaquim Ribeiro de Avellar, também residente de Paty do Alferes. Este,

\footnotetext{
${ }^{4}$ Maiores informações acerca de professores pretos, livres ou libertos ver as pesquisas: SILVA, Adriana Maria Paulo da. A Escola de Pretextato dos Passos e Silva: questões a respeito das práticas de escolarização no mundo escravista. Revista Brasileira de História da Educação. no. 4. jul./dez. 2002; MARTINEZ, Alessandra Frota (1996). Educar e instruir. A instrução popular na corte imperial (1870-1889). Dissertação (Mestrado em História) - Universidade Federal Fluminense, Niterói. RAMOS, Stephane. Patrícios negros: experiências de educação popular no Rio de Janeiro (1887-1956). Dissertação (Mestrado), Universidade Federal do Rio de Janeiro, Rio de Janeiro, RJ, 1010.; FIGUEIREDO, Higor Figueira. Com tintas de liberdade: professores, raça e cartografias da educação na Corte imperial. Tese (Doutorado), Universidade Federal do Rio de Janeiro, RJ, 2020.

${ }^{5}$ A família Ribeiro de Avellar foi rica proprietária de terras, cafezais e escravizados em Paty de Alferes. Para mais informações ver: MUAZE, Mariana de Aguiar Ferreira. Os guardados da Viscondessa: fotografia e memória na coleção Ribeiro Avellar. An. mus. paul. vol.14 no.2 São Paulo July/Dec. 2006. STEIN, Stanley J. Vassouras: um município brasileiro do café, 1850-1900. Tradução de Vera Bloch Wrobel. Rio de Janeiro: Nova Fronteira, 1990.
}

Revista da ABPN • v. 12, n. Ed. Especial - Caderno Temático: "Africanos, escravizados, libertos biografias, imagens e experiências atlânticas” • agosto de 2020, p. 392-409 
sob número de matrícula 11079, de 29 de agosto de 1872, cor preta, 64 anos, solteiro, ferreiro.

Importa mencionar que ambos se encontravam na faixa dos 60 anos de idade, possivelmente africanos (o documento não menciona a origem dos libertos), eram solteiros, portanto, libertos quando da assinatura da Lei Áurea. Neste cenário teria a condição jurídica influenciado no processo de alfabetização e letramento desses sujeitos? Seus proprietários pertenciam a uma das famílias mais importantes de Paty de Alferes, detentores de grandes fazendas e muitos escravizados. Da mesma forma atuavam na política local. As falas, os debates, cochichos e tensões em conversas no espaço privado de senhores poderia ter sido base para os conhecimentos que possibilitaram a construção dos argumentos expostos na carta pelos libertos? A capacidade de escuta, assimilação, apropriação dos escravizados contribuíram no processo de aprendizados diversos, dentre os quais os relativos às questões políticas?

A carta dos libertos de Paty do Alferes, portanto, contraria a visão médica de modo particular em nossa reflexão, e da sociedade brasileira do oitocentos de modo geral. Segundo o médico francês, Jean-Baptiste Alban Imber ${ }^{6}$, "a organisação do negro differe da do branco, não só pela côr, como tambem por huma limitação em sua organisação cerebral, que lhe não permitte levar ao mesmo gráo a extensão das suas faculdades intelectuais" (IMBERT, 1839, p. XVIV). Ora, se os africanos proibidos de frequentarem a escola formal aprendiam a ler, escrever e mais, a ler o mundo sob uma perspectiva peculiar, como defender o exposto no discurso médico posto em destaque? Como já mencionado, africanos e seus descentes, escravizados, libertos ou livres agiam, intervinham, mobilizavam diferentes saberes a seu favor na sociedade escravista do oitocentos. E, nesse sentido, como afirmar que sua capacidade intelectual era inferior à dos europeus? Que temores moviam a intervenção do estado à negação do acesso de africanos ao mundo das letras?

\footnotetext{
6 Médico francês que chegou ao Rio de Janeiro em 1831 atuando no estudo das doenças populares e produziu diferente obras dentre as quais o Manual do Fazendeiro. Ou tratado doméstico sobre as enfermidades dos negros, com primeira publicação em 1834, e a segunda em 1839. Seu trabalho foi utilizado por diferentes sujeitos, dentre os quais, um administrador de fazendas que oferecia seus serviços em anúncios de jornais no Rio de Janeiro informando utilizar o "método" de Imbert.
}

Revista da ABPN • v. 12, n. Ed. Especial - Caderno Temático: "Africanos, escravizados, libertos biografias, imagens e experiências atlânticas” • agosto de 2020, p. $392-409$ 
A lei número 1 de 1837 fora promulgada após a revolta dos malês, podendo ter sido uma estratégia para evitar o desenvolvimento de aprendizados escolares e das primeiras letras entre africanos. Afinal, os malês haviam provocado um temor na população branca e, portanto, seria melhor prevenir do que remediar novos conflitos, tensões, revoltas, ou, quem sabe, revoluções. Mas também outro elemento seria significativo. Após a lei de 1831, que tornava ilegal o tráfico de africanos, houve um crescimento significativo de sua entrada no Império do Brasil, pois "os navios passaram a vir mais abarrotados" (RODRIGUES, 2000. p. 79). Logo, o quantitativo de africanos cresceu significativamente.

As sociabilidades entre africanos e seus descendentes extrapolavam as regras impostas, social e culturalmente. Em documento localizado no Fundo de Secretaria de Polícia, depositado no Arquivo Público do Estado do Espírito Santo, datado de 20 de agosto de 1861, encontra-se a descrição de uma invasão a ranchos de quilombolas ${ }^{7}$. Escravizados fugidos que construíram para si local de sobrevivência sem, contudo, romper relações com suas antigas senzalas. Não se isolaram, ao contrário, construíram múltiplas sociabilidades para a sobrevivência do grupo, comercializando com pequenos proprietários e também comerciantes locais. O documento foi assinado pelas autoridades da região de Nova Almeida, distrito do atual município de Serra, no estado do Espírito Santo. Os elementos que compunham a apreensão das autoridades locais foram "entregues como pertencentes a um quilombola", acusado de roubos e assassinatos. O mais interessante para nossa análise estaria entre os pertences encontrados: "um folheto da segunda coleção de cartas para meninos aprenderem a ler", "uma cartilha", "dous pedaços de Compêndio de Orthografia", além dos "translado de escrituras de Liberdade". Papéis e escritos pertencentes ao mundo das letras. E, nesse sentido, quais seriam os interesses de um quilombola, para ter, entre seus pertences, livros e escritos para o ensino das primeiras letras? Talvez, o mais relevante seria questionarmos o porquê de as autoridades locais demonstrarem tamanha preocupação com tais documentos. Afinal, numa sociedade majoritariamente iletrada, o saber ler e escrever poderia significar diferentes poderes, inclusive para quilombolas. Se a lei de 1837 proibia o acesso de

\footnotetext{
7 Arquivo do Espírito Santo, Fundo Polícia da Província, Caixa 31, maço 114 e documentos 64 e 65 , Livros encontrados com quilombolas.
}

Revista da ABPN • v. 12, n. Ed. Especial - Caderno Temático: "Africanos, escravizados, libertos biografias, imagens e experiências atlânticas" • agosto de 2020, p. $392-409$ 
africanos à instituição escolar, como alguns deles tiveram acesso às primeiras letras? De que modo um quilombola detinha sob seu poder cartilha, compêndio de ortografia, materiais específicos para alfabetização?

Como mencionado acima, as conexões entre senzalas, quilombos, economias locais, revoltas, leis emancipacionistas e o mundo atlântico eram parte, senão o todo, do cotidiano da sociedade brasileira do oitocentos ${ }^{8}$. Em que medida os achados com o quilombola causavam infortúnios às autoridades locais? Afinal, exigia-se "dar providências", segundo a sabedoria do delegado que a recebeu. As sociabilidades demonstram os quão articulados poderiam ser os quilombolas no cenário escravista. Além de possuir todos os livros e escritos já indicados, o quilombola é mencionado pela "Índia Maria Genoveva", ao declarar a "um agregado de Soares" que o "quilombola a prepara com a escrita". Para além de possuir documentos referentes ao ensino das primeiras letras, esse quilombola também as ensinava a indígenas? E mais, segundo o autor do documento, a autoridade policial tinha "bastante fundamento para desconfiar-se não só ter o quilombola andado por diversas localidades, e não vir do Norte como dizem, [...] como também já existir a tempos neste município, ter nele quem o acoitasse", isso porque, "não consta ao menor aqui que ele soubesse alguma casa da qual tirasse tais objetos". Ser "acoitado" não significava ser protegido somente pelos seus, mas, provavelmente, por quem poderia ter ou obtinha lucros com a produção dos quilombos (GOMES, 2015, p. 89). Os conhecimentos da geografia local, em certa medida, também compunham os saberes daquele quilombola. $\mathrm{O}$ que certamente lhe garantia fuga e manobras contra as ações policiais.

Os objetos transportados pelo quilombola parecem ter ou ser materialmente elementos relevantes para serem carregados, guardados, protegidos, ainda que sob algum risco. A proibição posta em lei de acesso à escolarização formal permite inferir o quão valioso era uma cartilha ou um compêndio de ortografia para africanos e seus descendentes, fossem escravizados ou livres. Afinal, a lei não permitia que africanos,

\footnotetext{
${ }^{8}$ Ver reflexões mais recentes em: MACHADO, Maria Helena \& GOMES, Flávio dos Santos. Eles ficaram "embatucados", seus escravizados sabiam ler: abolicionistas, senhores e cativos leitores no alvorecer da liberdade. In: GOMES, Flávio, MAC CORD, Marcelo e ARAUJO, Carlos Eduardo Moreira de. (Org.). Rascunhos Cativos. Educação, escolas e ensino no Brasil escravista. Rio de Janeiro: 7Letras, 2017, pp. 253283.
}

Revista da ABPN • v. 12, n. Ed. Especial - Caderno Temático: "Africanos, escravizados, libertos biografias, imagens e experiências atlânticas” • agosto de 2020, p. $392-409$ 
ainda que livres, adentrassem nas escolas formais. Os códigos de leitura e escrita e seu domínio poderiam e, certamente, garantiam o letramento daqueles sujeitos, podendo tais saberes ser utilizados como forma de sociabilidade e usos diversos em prol de um coletivo. Nesse sentido, os domínios de tais códigos seriam fundamentais no acesso a, ou na tentativa de requerer a liberdade, de modo que o terceiro elemento encontrado com o quilombola, acusado de roubos e assassinatos, os "translados de escrituras de Liberdade", tornavam-se uma arma potencial contra os objetivos dos grandes proprietários de terras e escravizados do Brasil oitocentista.

Ações de repressão conduzidas por autoridades policiais, fazendeiros e seus agregados faziam parte do cotidiano daquela sociedade. Nelas, buscava-se encontrar grupos, ranchos e acampamentos improvisados de escravizados fugitivos, ou mesmo de quilombos já estabelecidos nas terras ou fronteiras de grandes propriedades. O que é demonstrado no documento em questão. O domínio, portanto, das letras tornava viável o acesso à legislação - para além do ouvir no espaço privado da casa grande -, corroborando negociações possíveis, como observa-se na carta redigida pelos libertos de Paty de Alferes à Ruy Barbosa, ao solicitar-se o uso dos 5\% do Fundo de Emancipação na educação dos filhos ${ }^{9}$. O ensino e o acesso a ele, uma vez mais, surge como questão relevante para africanos, livres, libertos ou escravizados. Ambos os documentos - embora com temporalidades distintas -, auxiliam na compreensão dos possíveis significados da escrita, da leitura e dos letramentos, para africanos e seus descentes.

Que significados, todavia, teria a denominação "comissão" para os "libertos de Paty de Alferes"? Certamente, ela sugere perspectivas políticas e expectativas coletivas de pôr em evidência suas questões, sugestões e desejos. O contexto político e temporal nos permite perceber a complexidade de seus significados e sua escrita, enquanto mecanismo de mobilização e de estratégia coletivas. A Lei de 28 de setembro de 1871 fazia parte do projeto de emancipação lenta e gradual da escravidão. Ao mencionarem o Fundo de Emancipação, aqueles libertos tentavam mobilizar o destinatário, Rui Barbosa, por ter sido ele um dos políticos que comandaram o Fundo de Emancipação, tendo

\footnotetext{
${ }^{9}$ Sobre o documento escrito pelos sete libertos de Paty de Alferes ver: VIANA, Iamara da Silva; GOMES, Flávio dos Santos \& RIBEIRO NETO, Alexandre. "Escritos insubordinados entre escravizados e libertos no Brasil”. Estudos Avançados, volume 33, Instituto de Estudos Avançados/USP, 2019, pp. 55-177.
}

Revista da ABPN • v. 12, n. Ed. Especial - Caderno Temático: "Africanos, escravizados, libertos biografias, imagens e experiências atlânticas” • agosto de 2020, p. $392-409$ 
participado também dos debates acerca da Lei do Ventre Livre. Os libertos viam em Rui Barbosa um "verdadeiro defensor do povo". E mais, era, "entre os jornalistas", o que "assumiu posição definida e digna" sobre os "acontecimentos, que vieram enlutar nossos corações de patriotas". Mobilizaram argumentação sobre a mesma lei, posto não ter sido ela colocada em prática no tocante à educação dos ingênuos. Na verdade, a lei de 28 de setembro de 1871 nunca fora posta em execução quanto à parte que tratava da educação dos ingênuos, os filhos nascidos livres de mães escravizadas ${ }^{10}$.

Africanos desfilavam corpos quase nus na cidade corte. Para olhares europeus, algo inaceitável! Contudo, a diáspora não lhes retirou somente vestimentas, mas também família, propriedades, casa, ofícios, identidade, humanidade. Enfim, adentrar no mundo escravista não significou efetivamente um recomeço, mas, ao contrário, o fim de existências, tais quais foram um dia. Ressignificar laços de solidariedade, de família e de sobrevivência foi possível. Irmandades, quilombos ou casas de zungus possibilitaram encontros, reencontros e fugas. As religiosidades, as danças, as capoeiras teciam redes concretas de acalento. Os infortúnios para a população africana e seus descendentes eram muitos, como bem já demonstrado pela historiografia mais recente sobre a escravidão brasileira. Muitas doenças interferiam nos padrões desejáveis de produção e mão de obra nas fazendas produtoras de café.

E aqui retomo o fio condutor desta análise. O Artigo $3^{\circ}$. da Lei número 1, de 1837, também impedia que "todas as pessoas que padecerem moléstias contagiosas" frequentasse as escolas de instrução primária. As moléstias contagiosas eram temidas pela rapidez com que ceifavam vidas. Estando a medicina, no século XIX, em desenvolvimento, outros sujeitos que dominavam diferentes saberes de cura atuavam nos espaços urbanos e rurais. Curandeiros, feiticeiros, boticários, sangradores e parteiras dominavam os saberes das artes de curar e colaboravam no atendimento aos enfermos; contudo, a mortalidade escrava alcançava quantitativos relevantes para a economia de proprietários ${ }^{11}$. O medo do contágio aumentava, se pensado em ambientes fechados,

\footnotetext{
${ }^{10}$ Sobre o Fundo de Emancipação e seus impactos na sociedade oitocentista ver a pesquisa de ASSIS, Cátia da Costa Louzada de. Fundo de Emancipação e família escravas: o município neutro na lei de 1871. Dissertação (Mestrado) Universidade Federal do Rio de Janeiro, Rio de Janeiro, 2013

${ }^{11}$ Pesquisas importantes acerca dos diferentes agentes que dominavam as práticas de cura no século XIX são apresentados nas pesquisas: PIMENTA, Tânia Salgado. Sangradores no Rio de Janeiro na primeira metade do oitocentos. In: Ângela Porto (Org.). Doenças e escravidão: sistema de saúde e práticas
}

Revista da ABPN • v. 12, n. Ed. Especial - Caderno Temático: "Africanos, escravizados, libertos biografias, imagens e experiências atlânticas” • agosto de 2020, p. $392-409$ 
insalubres, com pouca entrada de ar e luz, podendo ser este um dos motivos para sua imposição na lei. Produzi a tabela 1 para demonstrar quantitativamente a incidência de mortes por doenças infectocontagiosas e seu impacto entre escravizados, libertos e livres.

Tabela 1 - Comparação de escravos e livres por tipo de doenças e gênero, 1840-1880

\begin{tabular}{|c|c|c|c|c|c|c|c|c|c|c|}
\hline Grupo & \multicolumn{3}{|c|}{ Escravos } & \multicolumn{6}{c|}{ Livres } \\
\cline { 2 - 11 } & $\mathrm{H}$ & $\%$ & $\mathrm{M}$ & $\%$ & $\mathrm{~T} \%$ & $\mathrm{H}$ & $\%$ & $\mathrm{M}$ & $\%$ & $\mathrm{~T} \%$ \\
\hline $\begin{array}{c}\text { Infecto- } \\
\text { Parasitárias }\end{array}$ & 36 & 12.90 & 24 & 8.60 & 21.50 & 114 & 16.15 & 94 & 13.31 & 29.46 \\
\hline $\begin{array}{c}\text { Sistema } \\
\text { Circulatório }\end{array}$ & 13 & 4.66 & 18 & 6.45 & 11.11 & 35 & 4.96 & 15 & 2.13 & 7.09 \\
\hline $\begin{array}{c}\text { Sistema } \\
\text { Digestivo }\end{array}$ & 8 & 2.87 & 4 & 1.43 & 4.30 & 24 & 3.40 & 7 & 0.99 & 4.39 \\
\hline $\begin{array}{c}\text { Sistema Nervoso } \\
\text { e } \\
\text { Neuropsiquiátrico }\end{array}$ & 15 & 5.37 & 7 & 2.51 & 7.89 & 31 & 4.39 & 16 & 2.27 & 6.66 \\
\hline $\begin{array}{c}\text { Sistema } \\
\text { Respiratório }\end{array}$ & 19 & 6.81 & 5 & 1.79 & 8.60 & 11 & 1.56 & 9 & 1.27 & 2.83 \\
\hline $\begin{array}{c}\text { Sistema } \\
\text { Osteomuscular e } \\
\text { Reumático }\end{array}$ & 2 & 0.72 & 2 & 0.72 & 1.44 & 3 & 0.42 & 2 & 0.28 & 0.71 \\
\hline $\begin{array}{c}\text { Morte Violenta } \\
\text { ou Acidental }\end{array}$ & 11 & 3.94 & 3 & 1.07 & 5.01 & 25 & 3.54 & 6 & 0.85 & 4.39 \\
\hline Primeira Infância & 0 & - & 1 & 0.36 & 0.36 & 21 & 2.97 & 14 & 1.98 & 4.95 \\
\hline Gravidez e Parto & - & - & 4 & 1.43 & 1.44 & - & - & 14 & 1.98 & 1.98 \\
\hline $\begin{array}{c}\text { Causas mal } \\
\text { definidas }\end{array}$ & 71 & 25.45 & 36 & 12.90 & 38.35 & 132 & 18.70 & 117 & 16.57 & 35.27 \\
\hline $\begin{array}{c}\text { Doenças } \\
\text { Geniturinárias }\end{array}$ & - & - & - & - & - & 2 & 0.28 & 1 & 0.14 & 0.42 \\
\hline Doenças de Pele & - & - & - & - & - & 1 & 0.14 & - & - & 0.14 \\
\hline $\begin{array}{c}\text { Doenças } \\
\text { Conhecidas }\end{array}$ & - & - & - & - & - & 2 & 0.28 & 3 & 0.42 & 0.71 \\
\hline Idade Avançada & - & - & - & - & - & 3 & 0.42 & 4 & 0.57 & 0.99 \\
\hline Totais & 175 & 62.72 & 104 & 37.28 & 100 & 404 & 57.22 & 302 & 42.78 & 100 \\
\hline Total Geral: & & & 279 & & & & & 706 & & \\
\hline Fonte Livos & 0 & & & & & & & & & \\
\hline
\end{tabular}

Fonte: Livros de Óbitos das pessoas escravas e livres da Paróquia de Nossa Senhora da

Conceição de Vassouras. Centro de Documentação História da Universidade Severino Sombra /

$\mathrm{CDH}$.

terapêuticas. Rio de Janeiro: Casa de Oswaldo Cruz / Fiocruz, 2007.; XAVIER, Regina. SAMPAIO, Gabriela.; NOGUEIRA, André. Doenças, feitiços e curas: africanos e seus descendentes em ação nas Minas do século XVIII. In: Ângela Porto (Org.). Doenças e escravidão: sistema de saúde e práticas terapêuticas. Rio de Janeiro: Casa de Oswaldo Cruz / Fiocruz, 2007.; SAMPAIO, Gabriela dos Reis. Juca Rosa: um paide-santo na Corte imperial. Rio de Janeiro: Arquivo Nacional, 2009.; XAVIER, Regina Célia Lima. Religiosidade e escravidão, século XIX: mestre Tito. Porto Alegre: Editora da UFRGS, 2008

Revista da ABPN • v. 12, n. Ed. Especial - Caderno Temático: "Africanos, escravizados, libertos biografias, imagens e experiências atlânticas” • agosto de 2020, p. 392-409 
A tuberculose, segundo dados de pesquisa para o município de Vassouras, entre os anos de 1840 e 1880, era uma das causas mortis mais presentes entre escravizados, libertos e livres. Pertencente ao grupo das doenças Infecto-parasitárias, resultou em $10.03 \%$ (28) de óbitos de cativos para todo o período analisado. Entre os livres, gerou $16.57 \%$ (117) de mortes, nesse grupo de moléstias. Segundo Mary Karasch (2000, p. 209-212), esta era uma doença antiga em todos os continentes, inclusive na América, não podendo ser pensada como atingindo especialmente escravizados. Nas cidades europeias ou americanas, durante a primeira metade do século XIX, a tuberculose era considerada epidêmica, a principal causa de morte da população. Atingia todas as classes sociais, mas as populações rurais deslocadas para as cidades eram as mais suscetíveis (CARVALHO, 2007, p. 7).

Nos óbitos analisados da Paróquia de Nossa Senhora da Conceição de Vassouras, ao se compararem as informações com outras doenças que provocaram mortes, percebe-se quantidade significativa de escravizados, de libertos e de livres que morreram devido à tuberculose. Do total de mulheres do Livro de Óbito de livres atingidas por essa moléstia, 6 eram pretas $(0.84 \%), 20$ brancas $(2.83 \%), 12$ pardas $(1.70 \%)$ e $11(1.56 \%)$ sem cor atribuída. O total de descendentes de escravizadas é próximo ao de brancas, se forem consideradas conjuntamente pretas e pardas. Entre os escravizados, 12 mulheres (4.30\%) e 16 homens $(5.73 \%)$ foram atingidos mortalmente pela doença, de modo que percebemos a tuberculose com alcance entre diferentes classes sociais e distintas etnias que compunham a sociedade da Vassouras oitocentista.

Bexiga, ou varíola como também era conhecida, ocupa o segundo lugar dentro do grupo das moléstias infectocontagiosas no quantitativo de óbitos entre escravizados. Se a vacinação, ainda em território africano, diminuiu a incidência de casos da doença, entre os cativos de Vassouras, não fora possível, naquele momento, confirmar a informação. Entretanto, 7 (2.50\%) escravos sucumbiram a ela, $1(0.36 \%)$ homem e $6(2.15 \%)$ mulheres. Entre os livres, essa enfermidade foi fatal para $11(1.56 \%)$ indivíduos, 4 $(0.57 \%)$ homens e $7(0.99 \%)$ mulheres. Nos parece evidente ter sido o gênero feminino o grupo mais atingido pela doença; entre os grupos, percentualmente o dos escravizados.

A febre amarela apresentava peculiaridade, posto que o indivíduo estaria imunizado por alguns anos, se fosse infectado em algum momento de sua vida. A falta de

Revista da ABPN • v. 12, n. Ed. Especial - Caderno Temático: "Africanos, escravizados, libertos biografias, imagens e experiências atlânticas” • agosto de 2020, p. $392-409$ 
contato anterior com a infecção levou muitos estrangeiros livres à morte, conforme nos informa Mary Karasch (2000, p. 222-223). Na análise do livro de óbitos de escravizados, ainda seguindo a tabela 1, nenhum caso da doença ocasionou morte neste grupo. Entre os livres, contudo, significou a morte de 11 homens e 2 mulheres, representando $6.25 \%$ das causas mortis no grupo de doenças infecto-parasitárias e $1.84 \%$ do total das moléstias quantificadas.

Tabela 2 - Doenças de escravos listadas nos Registros Religiosos e nos Inventários de proprietários

\begin{tabular}{|l|c|c|c|c|}
\hline \multicolumn{1}{|c|}{ Grupo de Moléstias } & Livros de Óbitos & $\%^{*}$ & Inventários & $\%^{*}$ \\
\hline Infecto-parasitárias & 60 & 21.51 & 50 & 2.44 \\
\hline Sistema Circulatório & 31 & 11.11 & 12 & 0.58 \\
\hline Sistema Digestivo & 12 & 4.30 & 9 & 0.44 \\
\hline Sistema Nervoso & 22 & 7.89 & 2 & 0.10 \\
\hline Sistema Respiratório & 24 & 8.60 & 43 & 2.10 \\
\hline Osteomuscular & 4 & 1.44 & 51 & 2.48 \\
\hline Causas Violentas / Defeitos diversos & 14 & 5.01 & 963 & 46.97 \\
\hline
\end{tabular}

Fonte: Registros de Óbitos de escravos e Inventários post mortem, 1840-1880. CDH.

*Percentuais calculados com base nos totais de cada fonte para cada grupo de doenças.

Nos inventários - documentos com objetivos econômicos, de posse e hereditariedade -, as doenças são informadas, tendo como um dos principais critérios, o valor atribuído ao escravizado, que, para pequenos proprietários, poderia ser o maior e mais caro bem. O que interessava, nesse tipo de documento, eram as mazelas deixadas pelas moléstias ou castigos, o que impossibilitaria o cativo para o trabalho, diminuindo o valor do patrimônio a ser considerado e, consequentemente, da mão de obra necessária para as diversas atividades da fazenda. Para ilustrar as divergências em ambos os documentos, elaborei a tabela dois, quantificando o número de vezes que as principais doenças relacionadas a cada grupo foram registradas.

Corpus documentais diferentes, objetivos e perspectivas igualmente distintas. Nos inventários post mortem de proprietários eram catalogadas doenças ou imperfeições dos cativos. Se compararmos estas com as que causavam a morte, teremos uma inversão da relevância e dos valores atribuídos a cada um dos grupos de moléstias. Assim, se entre os escravizados, nos livros paroquiais, as doenças infecto-parasitárias eram as responsáveis pelo maior número de óbitos, nos inventários, elas significam apenas $2.44 \%$ (50) do total

Revista da ABPN • v. 12, n. Ed. Especial - Caderno Temático: "Africanos, escravizados, libertos biografias, imagens e experiências atlânticas” • agosto de 2020, p. $392-409$ 
dos infortúnios morbos. Aquelas relacionadas ao sistema respiratório somavam 8.60\% no registro religioso; nos inventários, representam $2.10 \%$ do total. Maior impacto percebese nos registros das moléstias que geravam "defeitos" e diferentes deficiências. Considerando moléstias relacionadas à visão, audição, invalidez, obesidade, defeitos nos membros inferiores e superiores, teremos um total de $46.97 \%$. Portanto, quase metade dos escravizados relacionados nos inventários post mortem de proprietários de Vassouras, entre os anos de 1840 a 1880, com algum problema de saúde, teve ou tinha problemas físicos gerados por moléstias, castigos ou acidentes. Considera-se que a relação existente entre imperfeições, moléstias e patrimônio norteava as anotações feitas nos inventários post mortem. Essas informações também indicam os maus tratos defendidos por muitos fazendeiros, como forma de manutenção da ordem escravista, descrita nos manuais da década de 1830.

Esse cenário contribui para afastamento de indivíduos indesejados nos espaços escolares. Fossem eles brancos, ou crioulos livres. Informações da alta mortalidade, por doenças infectocontagiosas entre os africanos e seus descendentes, levam-nos a inferir que o artigo $3^{\circ}$. da lei de 1837 corroborava o distanciamento desses sujeitos dos códigos de escrita e leitura, quiçá da possibilidade de letramento. De fato, moléstias infectocontagiosas, como tuberculose e febre amarela, impossibilitavam o indivíduo para uma vida em comunidade, bem como, para o trabalho e, certamente, para o acesso à escola formal ou informal.

\section{CONSIDERAÇÕES FINAIS}

Papéis, tinta e letras estavam presentes nas fugas, rebeliões, negociações e conquistas. O mundo letrado no século XIX contou com indivíduos negros livres, mas, escravizados e libertos nem sempre puderam contar com a possibilidade de acesso aos "bancos escolares" $" 12$. Os documentos históricos utilizados para esta reflexão nos permitem adentrar - de modo direto ou indireto - em questões, medos, desejos, negociações,

\footnotetext{
${ }^{12}$ Sobre indivíduos negros inseridos no mundo das letras ver a pesquisa: PINTO, Ana Flávia Magalhães. Escritos de Liberdade: literatos negros, racismo e cidadania no Brasil oitocentista. Campinas, SP: Editora da Unicamp, 2018.
}

Revista da ABPN • v. 12, n. Ed. Especial - Caderno Temático: "Africanos, escravizados, libertos biografias, imagens e experiências atlânticas” • agosto de 2020, p. 392-409 
conhecimentos, lutas e protagonismos de africanos, livres, libertos ou escravizados, na complexa sociedade escravista brasileira do oitocentos. Embora o Estado, por meio de suas leis, proibisse o acesso de africanos, mesmo os livres, à escolarização formal, eles encontraram diferentes modos de decifrarem os códigos de escrita, leitura - incluindo a de mundo - e liberdades.

Dominar os códigos de leitura escrita, naquele início do século XIX, ampliaria possibilidades de inserção social, aumento de capital e poder. A sociedade contava com uma grande maioria de não letrados, o que, em certa medida, pode configurar tensões e disputas. Além dos enfermos, os escravizados e os africanos - mesmo livres ou libertos - não poderiam ter acesso à instrução primária no Rio de Janeiro. As portas das escolas públicas permaneceram fechadas para aqueles sujeitos. A negação da escrita, na forma da lei, aponta o direito ao letramento e aos códigos de leitura e escrita somente aos indivíduos brancos ou crioulos livres. Por não serem mencionados, pressupõe-se a possibilidade de acesso destes à escola pública. Isso não significa dizer que efetivamente tivessem acesso ao "mundo das letras".

Questões presentes na sociedade atual. A população negra ainda requer liberdades (de ir e vir, de trabalho, de estudo, de acesso, de direitos etc.) e escolarização. Mesmo com a Constituição de 1988, definindo a educação como direito de todo cidadão, nem todos conseguem permanecer na escola, concluir o ensino básico ou adentrar numa universidade. A construção histórica, que teve por base os mais de 250 anos de escravização da população africana e de seus descendentes, possibilitou enorme desigualdade social, econômica e política. O período pós-emancipação no Brasil não conseguiu garantir igualdade e equidade para a população negra. Nesse sentido, precisamos ir além do escrito nas leis, das palavras, da tinta impressa. Ações contundentes contra o racismo e a desigualdade, são fundamentais para a ressignificação do ser negro, o que possibilitará equidade para cidadãos, independentemente de seu fenótipo.

\section{REFERÊNCIAS BIBLIOGRÁFICAS}

Fontes:

BRASIL, Lei n.1 de 1837, e o Decreto no. 15 de 1839. Coleção Leis do Império.

Revista da ABPN • v. 12, n. Ed. Especial - Caderno Temático: "Africanos, escravizados, libertos biografias, imagens e experiências atlânticas" • agosto de 2020, p. $392-409$ 
IMBERT J. B. A. Manual do Fazendeiro. Ou tratado doméstico sobre as enfermidades dos negros. $2^{\mathrm{a}}$. ed. Rio de Janeiro: Typografia Nacional, 1839.

Jornal O Vassourense. 1886. Edições 24 e 25.

SIGAUD, J.F.X. Do clima e das doenças do Brasil ou estatística médica deste império. Tradução de Renato Aguiar. Rio de Janeiro: Editora Fiocruz, 2009.

Bibliografia:

CARVALHO, Diana Maul de. Doenças dos escravizados, doenças africanas? In: Ângela Porto (Org.). Doenças e escravidão: sistema de saúde e práticas terapêuticas. Rio de Janeiro: Casa de Oswaldo Cruz / Fiocruz, 2007.

GOMES, Flavio. Negros e política (1888-1937). Rio de Janeiro: ZAHAR, 2005.

KARASCH, Mary C. A Vida dos Escravos no Rio de Janeiro (1808-1850). Tradução: Pedro Maia Soares. São Paulo: Companhia das Letras, 2000.

MARQUESE, Rafael de Bivar. Feitores do corpo, missionários da mente: senhores, letrados e o controle dos escravos nas Américas, 1660-1860. São Paulo: Companhia das Letras, 2004.

MORTARI, Claudia; DEBORTOLI, Gabrielli. Experiências em diáspora: africanas e africanos numa cidade portuária ao sul do Brasil (Desterro, 1810-1860). Revista Brasileira de Pesquisadores/as Negros/as (ABPN), [S.1.], v. 7, n. 17, p. 247-270, out. 2015. ISSN 2177-2770. Disponível em: https://bit.ly/3eu6S2O. Acesso em 13 de jun. 2020.

MUAZE, Mariana de Aguiar Ferreira. Os guardados da Viscondessa: fotografia e memória na coleção Ribeiro Avellar. An. mus. paul. vol.14 no.2 São Paulo July/Dec. 2006.

NETO, Alexandre Ribeiro. Acalanto: ensinando as primeiras letras aos filhos de libertos em Vassouras (1871-1910). In: CORD, Marcelo Mac; ARAÚJO, Carlos Eduardo Moreira de; GOMES, Flávio dos Santos (orgs). Rascunhos Cativos: educação, escolas e ensino no Brasil escravista. 1. ed. Rio de Janeiro: 7 Letras, 2017.

NOGUEIRA, André. Doenças, feitiços e curas: africanos e seus descendentes em ação nas Minas do século XVIII. In: Ângela Porto (Org.). Doenças e escravidão: sistema de saúde e práticas terapêuticas. Rio de Janeiro: Casa de Oswaldo Cruz / Fiocruz, 2007.

PIMENTA, Tânia Salgado. Sangradores no Rio de Janeiro na primeira metade do oitocentos. In: Ângela Porto (Org.). Doenças e escravidão: sistema de saúde e práticas terapêuticas. Rio de Janeiro: Casa de Oswaldo Cruz / Fiocruz, 2007.

PINTO, Ana Flávia Magalhães. Escritos de Liberdade: literatos negros, racismo e cidadania no Brasil oitocentista. Campinas, SP: Editora da Unicamp, 2018.

REIS, João José e SILVA, Eduardo. Negociação e Conflito: a Resistência negra no Brasil Escravista. São Paulo: Companhia das Letras, 1989.

SALLES, Ricardo Henrique. E o Vale era o Escravo: Vassouras, século XIX - Senhores e escravos no coração do império. Rio de Janeiro: Civilização Brasileira, 2008.

Revista da ABPN • v. 12, n. Ed. Especial - Caderno Temático: "Africanos, escravizados, libertos biografias, imagens e experiências atlânticas" • agosto de 2020, p. 392-409 
SILVA, Marilene Rosa Nogueira da. Negro na Rua: a nova face da escravidão. São Paulo: Hucitec, 1988.

SOARES, Carlos Eugênio Líbano. Zungú: rumor de muitas vozes. Rio de Janeiro: Arquivo Público do Estado do Rio de Janeiro, 1998.

SOARES, Magda. Novas práticas de leitura e escrita: letramento na cibercultura. Educação e Sociedade. Vol. 23. no. 81. Campinas, 2002.

SPIX e MARTIUS. Viagem pelo Brasil: 1817-1820. trad. Lúcia Furquim Lahmeyer. 3 ed. São Paulo: Melhoramentos; Brasilia, INL, 1976.

STANLEY, Stein. Vassouras: um município brasileiro do café, 1850-1900. Rio de Janeiro: Nova Fronteira, 1990.

VIANA, Iamara da Silva. Corpos escravizados e saber médico: proposições de Jean-Baptiste Alban Imbert (1830-1850). Tese (Doutorado) Universidade do Estado do Rio de Janeiro, Rio de Janeiro, 2016.

. Morte escrava e relações de poder em Vassouras (1840-1880): hierarquias raciais, sociais e simbolismos. Dissertação (Mestrado) Universidade do Estado do Rio de Janeiro, Rio de Janeiro, 2009.

Recebido em: 10/07/2020

Aceito em: $29 / 07 / 2020$

Revista da ABPN • v. 12, n. Ed. Especial - Caderno Temático: "Africanos, escravizados, libertos biografias, imagens e experiências atlânticas" • agosto de 2020, p. $392-409$ 